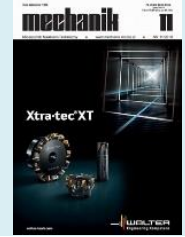

Authors: Małgorzata Poniatowska, Damian Groch

Title of article: „Poprawa dokładności dopasowania powierzchni zamykających formy wtryskowej” (“Improving accuracy of fitting of closing surfaces in an injection mold")

Mechanik, Vol. 91, No. 11 (2018): pages 950-952

DOI: https://doi.org/10.17814/mechanik.2018.11.167

\title{
Improving accuracy of fitting of closing surfaces in an injection mold
}

\author{
Poprawa dokładności dopasowania powierzchni \\ zamykających formy wtryskowej
}

\begin{abstract}
MALGORZATA PONIATOWSKA DAMIAN GROCH *
\end{abstract}

The methodology for improving the accuracy of fitting the cooperating surfaces of the freeform is presented. It involves introducing corrections to the machining program and then performing the correcting machining of one of the surfaces. The basis for determining the corrections is the CAD model of the gap.

KEYWORDS: accuracy of fitting, freeform surfaces, CAD model of the gap, correcting machining

Currently, the use of injection molds is one of the main ways of producing different products. In the machining of complex mold and die surfaces, machining is performed on multi-axis machining centers. In addition to the quality of molds, it must ensure its proper functioning. An important problem in the milling of injection molds is the achievement of an adequate accuracy of the matching of the closing surfaces, which are often free in shape. Deviations of surfaces processed from the nominal shape cause a leak in the joint and, as a result, a plastic leak.

In the literature on multi-axis milling of the free-form surfaces, much attention is paid to improving the accuracy of the surface treated. One approach is to analyze and model the sources of processing errors and their impact on product quality [1, 2]. Another approach is to analyze surface deviations after machining and to improve accuracy by modifying the machining program. One of the methods is to introduce compensating corrections based on raw measurement data [3].

Measurements of the freeform surfaces are most often carried out on numerically controlled coordinate measuring machines (CMMs), equipped with contact measuring heads [4]. The result of the measurement is a set of points with a specific distribution on the surface. For each measuring point a local deviation is determined, i.e. the distance of the measurement point from the CAD model in the normal direction. Then the nominal CAD model is modified by adding local deviations with the opposite sign. Measurement data contain information on deterministic and random phenomena occurring on the surface as a result of the machining process, and measurement noise $[5,6]$. Due to the spatial variation of spatially-variable curvature are: the distribution of cutting forces and other phenomena accompanying the treatment. As a result, the distribution of deviations has the same character. In order to separate the unwanted random component from spatial measurement data, it is possible to apply regression analysis and methods of spatial statistics $[6,7]$.

The problem of geometrical accuracy becomes more complex when two surfaces are associated, especially when a tight fit is required. In combination, the deviations of both surfaces add up. This is the case with injection mold closing surfaces.

The article proposes a methodology for the correction of machining errors of the cooperating freeform surfaces. It consists in improving the accuracy of their matching by introducing compensating corrections to the machining program of one of the surfaces. The basis of the methodology are CAD models of actual surfaces, determined on the basis of data obtained from measurements on CMM according to the regular grid of points. The model determination procedure uses: regression analysis, iterative procedure, NURBS modeling [8] and spatial statistics tests [9]. When models are available, simulation testing of joint tightness can be performed in the CAD software. It is then possible to determine the spatial CAD model of the gap between the surfaces and use this model to determine compensating corrections in the second processing step.

\section{Description of the methodology}

In the proposed method of improving the accuracy of matching two freeform surfaces, the results of simulation tests of joint tightness are used. Actual surfaces CAD models (MASes) determined on the basis of coordinate measurement data are necessary.

To obtain a virtual CAD model of the gap between the associated surfaces, MASes of both closing surfaces should be determined. Then the closing of both surfaces in the CAD software should be simulated. The defined virtual gap between the models in the CAD representation is the basis for determining the corrections compensating errors in the machining process. To improve the tightness of the joint, it is sufficient to apply the correcting treatment only to one of the closing surfaces.

\footnotetext{
* dr hab. inż. Małgorzata Poniatowska (m.poniatowska@pb.edu.pl)

- Katedra Inżynierii Materiałowej i Produkcji, Wydział Mechaniczny

Politechniki Białostockiej; mgr inż. Damian Groch

(groch.damian@gmail.com) - Bianar Sp. z o. o., Białystok
} 
- Acquisition of measurement data. In order to obtain data for carrying out the procedure, the measurements of both surfaces on the numerically controlled CMM should be made according to the regular point grid and the values of the measurement points deviations from the CAD models should be determined. It is therefore necessary to: locate the CAD object and model in a common coordinate system, generate nominal measurement points on the CAD model, perform a numerically controlled measurement and compare the designated measurement points with the corresponding points on the CAD model.

n Actual surface CAD modeling procedure. In the discussed methodology, on the measurement data, regression surfaces are modeled using the iterative procedure, NURBS modeling and Moran / spatial statistics. The determined smooth regression surfaces are the most probable representations of deviations determined in the measurements. By applying these models to the nominal CAD models, spatial models of actual surfaces are obtained. The procedure for determining MASes for closing surfaces is shown in fig. 1.

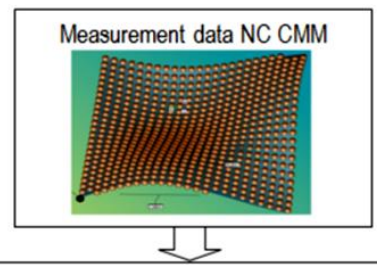

Testing spatial autocorrelation of data - Moran / statistics

$$
I=\frac{n}{S_{0}} \frac{r^{T} C r}{r^{T} r}
$$

where: $r$ - vector of model residuals

$C$-weighting matrix of spatial relations in $i$ and $j$ locations,

$$
S_{0}=\sum_{i=1}^{n} \sum_{j=1}^{n} c_{i j},(i \neq j)
$$

- Modeling surface representing deterministic deviations applying: regression analysis, iterative procedure, NURBS modeling [8];

- Testing spatial randomness of regression model residuals in the subsequent iterating steps applying: Kolmogorov-Smirnov test, Moran / statistics [9]

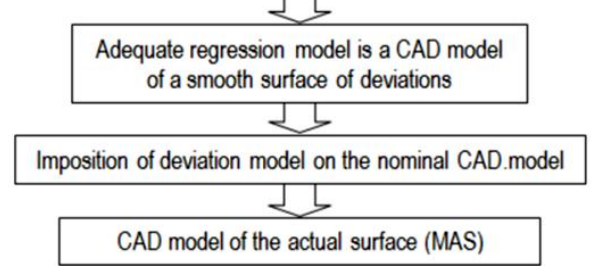

Fig. 1. Scheme of the procedure for determining MASes

n Determining corrections to compensate for the joint. Based on the MPRs of both surfaces, they can be simulated in the CAD software by approaching the inverted model of one surface to the model of the other surface in the direction of the $Z$ axis, excluding the remaining five degrees of freedom. The result of the simulation is a virtual CAD model of the gap between the surfaces. On its basis, corrections are determined at the measuring points to compensate for the sum of machining errors on both surfaces. At the next stage, the CAD model of one of the surfaces should be modified, adding the designated corrections, and generate on its basis the corrected path of the reprocessing tool.

\section{Experimental research}

The method was verified on the surfaces of free samples with the dimensions of $50 \times 50 \mathrm{~mm}$ base, made of WCLV steel (fig. 2). The machining was carried out on a free stand machining center. A spherical cutter with a diameter of 6 $\mathrm{mm}$, a rotational speed of $8000 \mathrm{rpm}$, a feed of $800 \mathrm{~mm} / \mathrm{min}$, two-sided machining in the $X Y$ plane was used.

Fig. 2. View of samples

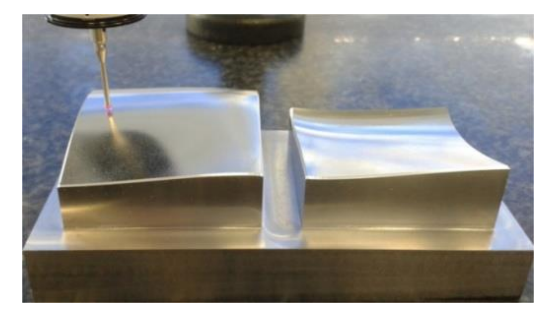

- Measurements on CMM. The measurements were performed on CMM GLOBAL Performance 070705 with SP25M head (PC DMIS software, $\left.\mathrm{MPE}_{\mathrm{E}}=1.5+\mathrm{L} / 333 \mu \mathrm{m}\right)$. A $20 \mathrm{~mm}$ measuring pin with a $\mathrm{d}=1 \mathrm{~mm}$ tip was used and 2,500 measuring points were measured according to the regular grid of $u \times v(50$ rows $\times 50$ columns $)$. Deviations were obtained with the distributions of values presented in fig. 3; deviation values are given in the tab. I.

\section{TABLE I. Values of the observed deviations}

\begin{tabular}{|l|c|c|}
\cline { 2 - 3 } \multicolumn{1}{c|}{} & Left surface & Right surface \\
\hline Average deviation, $\mathrm{mm}$ & $-0,0482$ & $-0,0516$ \\
\hline Minimum deviation, $\mathrm{mm}$ & $-0,0589$ & $-0,0596$ \\
\hline Maximum deviation, mm & $-0,0381$ & $-0,0395$ \\
\hline $\mid$ Max - Min|, mm & 0,0208 & 0,0201 \\
\hline
\end{tabular}

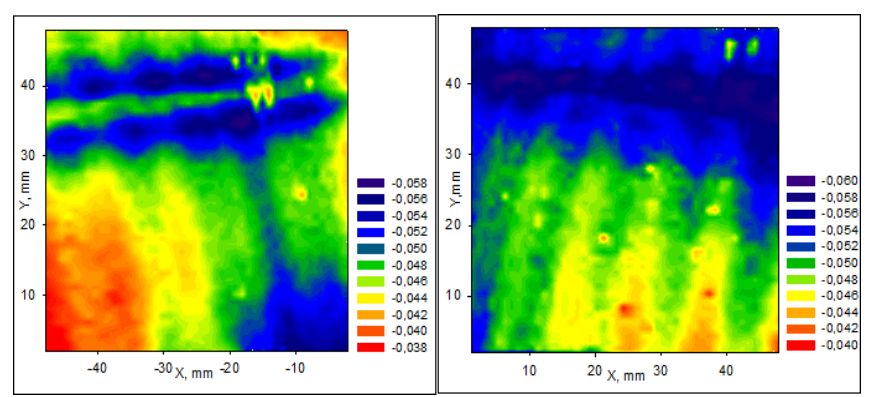

Fig. 3. Maps of observed deviations

- Setting corrections. The regression surfaces were modeled on the deviations obtained from the measurements in accordance with the diagram in fig. 1. In the iterative procedure, in subsequent steps the number of NURBS surface control points in both directions was changed (for subsequent surface stages 2 and 3), testing in each step $r$ model residuals. The regression model with the smallest number of control points and the lowest surface degrees in the directions $u$ and $v$ [10] was considered adequate for which model residuals met the criteria of normality of distribution and spatial randomness. An adequate regression models was obtained for the number of $31 \times 31$ control points and the $3 \times 3$ surface degrees of the left (convex) surface and for the number of control points of 29 $\times 29$ of the right (concave) surface. Mastercam X4 and Rhinoceros 3.0 software were used in modeling the surface. Maps of deviations determined from the models are shown in fig. 4, and statistical characteristics of the deviations are given in the tab. II. Models of deviations were imposed on the nominal CAD models - so MASes of both surfaces were obtained. In the simulation tests, a spatial CAD model of the gap between the surfaces was obtained. The map of the gap model width is presented in fig. 5 , and the gap dimensions are given in the tab. II. Corrections were determined in measurement points to compensate for the sum of machining errors as the inverse of local gap widths. The corrections received were added to the nominal CAD model of the left (convex) surface, and then a control program for corrective processing was generated. 


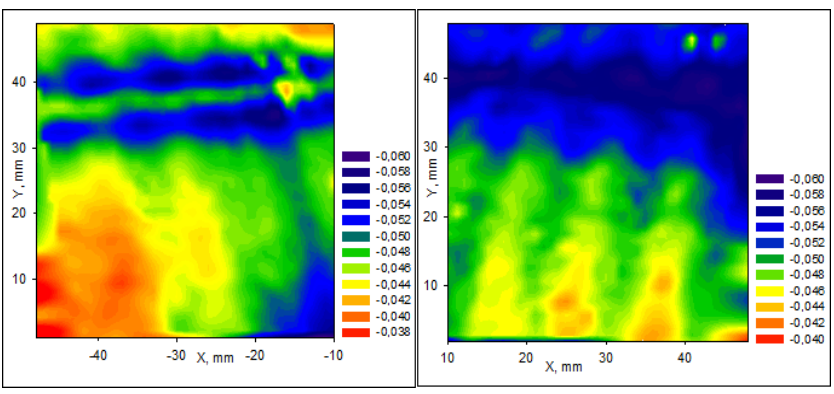

Fig. 4. Maps of deviations determined from models

TABLE II. Values of deviations determined from models

\begin{tabular}{|l|c|c|c|}
\cline { 2 - 4 } \multicolumn{1}{c|}{} & Left surface & Right surface & Gap \\
\hline $\begin{array}{l}\text { Average deviation, } \\
\text { mm }\end{array}$ & $-0,0482$ & $-0,0517$ & 0,0162 \\
\hline $\begin{array}{l}\text { Minimum deviation, } \\
\text { mm }\end{array}$ & $-0,0585$ & $-0,0591$ & 0,0000 \\
\hline $\begin{array}{l}\text { Maximum deviation, } \\
\text { mm }\end{array}$ & $-0,0389$ & $-0,0433$ & 0,0322 \\
\hline $\mid$ Max -Min|, mm & 0,0196 & 0,0158 & \\
\hline
\end{tabular}

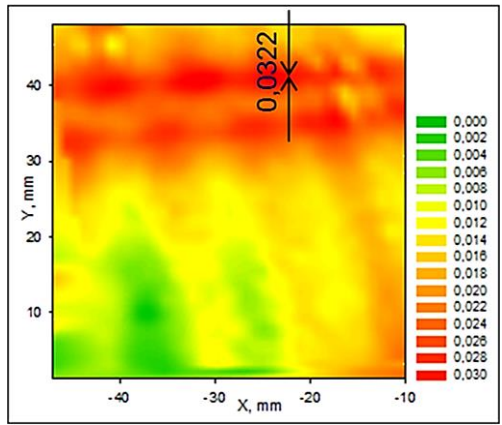

Fig. 5. Map of the width of the gap model before correction

- Assessment of the accuracy of surface fitting after correction. After corrective processing, measurements of the improved surface were made. Based on the deviations received, their CAD model was determined (according to fig. 1). An adequate regression model was obtained for the number of control points $28 \times 32$ and surface areas $3 \times 3$. The results of measurements and modeling are included in the tab. III, and fig. 6 shows the maps of deviations observed and determined from the model. On the basis of measurement data, MASes were determined, followed by a gap model (fig. 7).

As you can see, the width of the gap model between the surfaces after applying the correcting treatment decreased by about $80 \%$ (tab. II and tab. III).

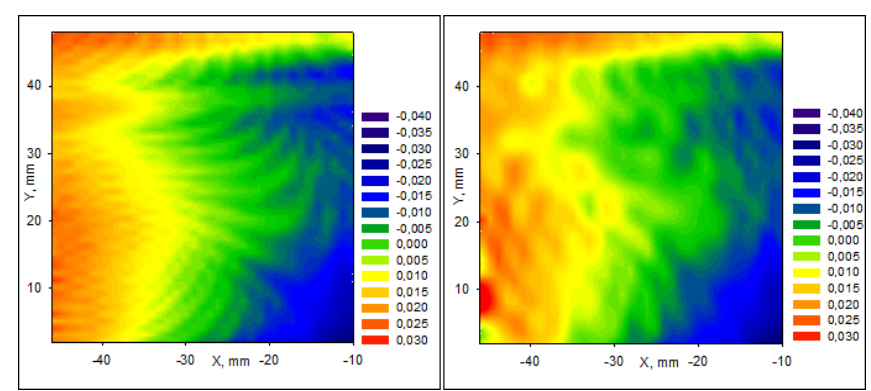

Fig. 6. Maps of deviations after correction: a) observed, b) determined from the model

TABLE III. Measurement and modeling results of deviations of the left (convex) surface after correction

\begin{tabular}{|l|c|c|c|}
\cline { 2 - 4 } \multicolumn{1}{c|}{} & $\begin{array}{c}\text { Observed } \\
\text { deviation }\end{array}$ & $\begin{array}{c}\text { Deviation de- } \\
\text { termined from } \\
\text { the model }\end{array}$ & Gap \\
\hline $\begin{array}{l}\text { Average } \\
\text { deviation, } \mathrm{mm}\end{array}$ & 0,0005 & 0,0007 & 0,0035 \\
\hline $\begin{array}{l}\text { Minimum } \\
\text { deviation, } \mathrm{mm}\end{array}$ & $-0,0369$ & $-0,0394$ & 0,0000 \\
\hline $\begin{array}{l}\text { Maximum } \\
\text { deviation, } \mathrm{mm}\end{array}$ & $+0,0337$ & $+0,0331$ & 0,0062 \\
\hline $\begin{array}{l}\mid \text { Max }- \text { Min } \mid, \\
\mathrm{mm}\end{array}$ & 0,0706 & 0,0725 & \\
\hline
\end{tabular}

Fig. 7. Map of the width of the gap model after correction

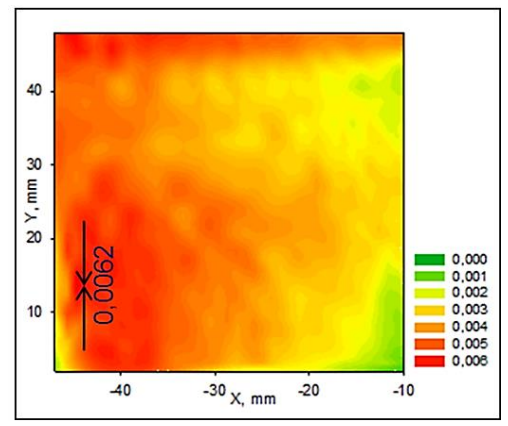

\section{Conclusions}

The presented methodology for improving the accuracy of fitting two freeform surfaces is used in the milling of injection mold surfaces. The corrections compensating the width of the gap between the surfaces are determined on the basis of simulation tests in CAD programs. The corrections determined from the CAD model of the gap are introduced into the program controlling the processing of one of the surfaces, and then a re-machining is carried out. The basis of the research are NURBS surface models, representing actual surfaces, which are determined on the basis of measurement data from a co-ordinate measuring machine. The advantage of this methodology in relation to the correction of errors of both surfaces is a reduction in the labor-intensity of the processing, because in the second stage only one of the surfaces is machined. Simulation and experimental tests confirmed an increase in the accuracy of fit by $80 \%$. After applying the correction, the width of the gap model decreased from 0.0322 to $0.0062 \mathrm{~mm}$.

The research was carried out as part of the work S/WM/2/2017 and financed from the funds for education of the Ministry of Science and Higher Education. The authors thank Bianar Sp. z o.o. Department of Tools Proofing in Bialystok for help in making samples for testing.

\section{REFERENCES}

1. Jia Z., Ma J., Song D., Wang F., Liu W. "A review of contouringerror reduction method in multi-axis CNC machining". International Journal of Machine Tools and Manufacture. Vol. 125

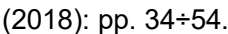

2. Uhlmann E., Abackerli A. J., Schutzer K., Lepikson H. A., Helleno A. L., Papa M. C. O., del Conte E. G., Mewis J. "Simulation and analysis of error impact on freeform surface milling". International Journal of Advanced Manufacturing and Technology. Vol. 70 (2014): pp. $607 \div 620$.

3. Werner A., Poniatowska M. "Error correction in complex-shape objects processing with numerical control milling machine". Archiwum Technologii Maszyn i Automatyzacji. Vol. 25, No. 2

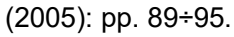

4. Sładek J. A.: "Coordinate Metrology: Accuracy of Systems and Measurements". Springer-Verlag, 2016. 
5. Colosimo B. M., Moroni G., Petro S. "A tolerance interval based criterion for optimizing discrete point sampling strategies". Precision Engineering. Vol. 34 (2010): pp. 745 $\div 54$

6. 7. Chena Y., Gao J., Deng H., Zhenga D., Chena X., Kelly R. "Spatial statistical analysis and compensation of machining errors for complex surface". Precision Engineering. Vol. 37 (2013): pp. $203 \div 12$

7. Poniatowska M. "Free-form surface machining error compensation applying 3D CAD machining pattern model". ComputerAided Design. Vol. 62 (2015): pp. $227 \div 235$.

8. Piegl L., Tiller W. "The NURBS book", 2nd ed. New York: Springer-Verlag, 1997.

9. Upton G. J. G., Fingleton B. "Spatial data analysis by example". Vol. 1. New York: John Wiley \& Sons, 1985.

Translation of scientific articles, their computer composition and publishing them on the website www.mechanik.media.pl by original articles in Polish is a task financed from the funds of the Ministry of Science and Higher Education designated for dissemination of science.

Ministry of Science and Higher Education

Republic of Poland 